\title{
MICROSTRUCTURE CHANGES AND OXIDATION RESISTANCE OF ALUMINIZED Ni-BASED SINGLE CRYSTAL SUPERALLOYS
}

\author{
Hideyuki Murakami and Kazuki Kasai ${ }^{1}$ \\ ${ }^{1}$ Surface and Interface Kinetics Group, Research Center for Structural Materials, National Institute for Materials Science (NIMS) \\ 1-2-1, Sengen, Tsukuba Science City, 305-0047, Japan
}

Keywords: Aluminize, Orientation, Recrystallization, Thermal history

\begin{abstract}
Microstructural changes and oxidation resistance of simply aluminized Ni-based single-crystal superalloys were systematically investigated. There are several kinds of microstructural changes observed in the as-aluminized Ni-based single crystal superalloys. For instance, in the case of a gritblasted specimen, secondary reaction zone (SRZ) was formed in the vicinity of substrate/coating interfaces. On the other hand, in the polished specimens, voids were formed by thermal cyclic heating. It is also found that grit-blasted specimens with SRZ formation exhibited accelerated oxidation. Microstructural changes are slightly accelerated along $<110>$ direction rather than $<100>$ direction. These experimental results can be explained by the recrystallization of substrate surfaces and subsequent interdiffusion between the coated layer and the substrate. Cyclic oxidation tests were also performed to assess the oxidation resistance of specimens with different microstructure and it is found that specimens with SRZ formation demonstrated worse oxidation resistance than those with voids formation, probably due to the difference in interdiffusion of solute elements between aluminized coatings and substrates.
\end{abstract}

\section{Introduction}

Aluminizing is one of the most cost-effective processes in enhancing the oxidation resistance of Ni-based superalloys, which are commercially used as turbine blades. By the aluminizing process, a NiAl-based $\beta$-phase, or $\mathrm{Ni}_{2} \mathrm{Al}_{3}$-based $\delta$-phase layer is formed on the surface of $\mathrm{Ni}$-based superalloy substrates consisting of $\mathrm{Ni}_{3} \mathrm{Al}$-based $\gamma^{\prime}$ and $\mathrm{Ni}$-solid solutioned $\gamma$ phases. The formation of Al-enriched surface layer results in the formation of stable $\mathrm{Al}_{2} \mathrm{O}_{3}$-based thermally grown oxide (TGO), and the TGO protects them against accelerated oxidation damages. The aluminizing process can be categorized as chemical vapor deposition (CVD) process accompanying solid state diffusion of $\mathrm{Al}$, and since substrate superalloys are single crystalline, microstructure of the Al-enriched surface layer can be affected by the crystal back scattered diffraction (EBSD) analysis, characterization of phases in aluminized superalloys, such as orientation relationship between substrates and coatings, has been conducted [1,2].

On the other hand, aluminized coatings can deteriorate the mechanical properties of substrate superalloys at high temperatures, because mechanical strength of bcc-structured phases has larger temperature dependence than that of fccstructured phases. In fact, it is reported that creep properties of aluminized superalloy can be determined by the effective cross section of un-damaged superalloy substrates [3]. The aluminizing process also deteriorates the mechanical properties of substrates by the precipitation of detrimental phases. When the aluminized turbine blades are exposed to high temperatures, critical microstructure changes can take place near the coating layer and the substrate, owing to the interdiffusion of alloying elements. One example is the formation of a secondary reaction zone (SRZ) [4], which can be defined as the region between the interdiffusion zone (IDZ) and the substrate that characteristically shows a high density of fine topologically close-packed (TCP) phase precipitates and a boundary at a high angle relative to the substrate [5]. The SRZ formation is led by any kind of coating process, such as thermal spraying [6], electron-beam physical vapor deposition [7], arc ion plating [8] and sputtered coatings [9]. Since the SRZ significantly degrades the mechanical properties and the creep resistance of the substrate [4], there are a number of reports focused on the formation kinetics of the SRZ in the aluminized superalloy substrates [1, 2, 4, 10-13] . To understand such microstructure changes of the aluminized coatings as well as to assess the oxidation resistance is thus important to totally evaluate the effectiveness of aluminizing processes. One of other interesting points is that Ni-based superalloy substrates inherently have microstructural anisotropy by the directionally solidifying fabrication process, and it is expected that thermo-mechanical properties can be affected by such anisotropic features. The authors' group indicated in the preliminary study that SRZ is preferentially formed along the $\{001\}<110>$ directions rather than the $\{001\}<100>$ directions $[6,14]$. The effect of secondary crystal orientation (surface crystal orientation) on creep properties of

Table I Nominal composition of Superalloys (mol\%)

\begin{tabular}{lllllllll|ll}
\hline & Co & Cr & Mo & W & Al & Ta & Hf & Re & Ru & Ni \\
\hline TMS-138 & 6.7 & 3.6 & 1.9 & 2.1 & 13.8 & 2.1 & 0.04 & 1.7 & 1.2 & Bal. \\
UCSX-8 & 6.7 & 1.9 & 2.4 & 2.1 & 11.4 & 2.9 & 0.0 & 2.1 & 1.9 & Bal. \\
\hline
\end{tabular}


Difference in coating procedure may also affect the subsequent microstructure of the components. For instance, there is a significant difference of microstructural changes between polished substrate surface and blasted ones [17, 18]. However, there are very few reports discussing the relationship between surface morphology and microstructure changes [19]. Above these as backgrounds, this study systematically investigates the microstructure changes and oxidation resistance of aluminized $\mathrm{Ni}$ based single-crystal substrates, with focusing on the effects of surface crystal orientation and difference in surface finishing prior to aluminizing process.

\section{Experimental Procedure}

The so-called $4^{\text {th }}$ generation Ni-based single crystal superalloys TMS-138 and UCSX-8 were used as the substrate materials. Nominal compositions of the alloys are listed in Table I. They were solution heat treated and cut along either $\{100\}$ or $\{110\}$ direction. Then various substrate surface finishes were employed. e.g., electropolishing, mechanical polishing and grid blasting. By applying different polishing methods, surface roughness $(\mathrm{Ra})$ of the specimens are controlled from less than $1 \mu \mathrm{m}$ (electropolishing, mechanical polishing) to 3 to $4 \mu \mathrm{m}$ (grid

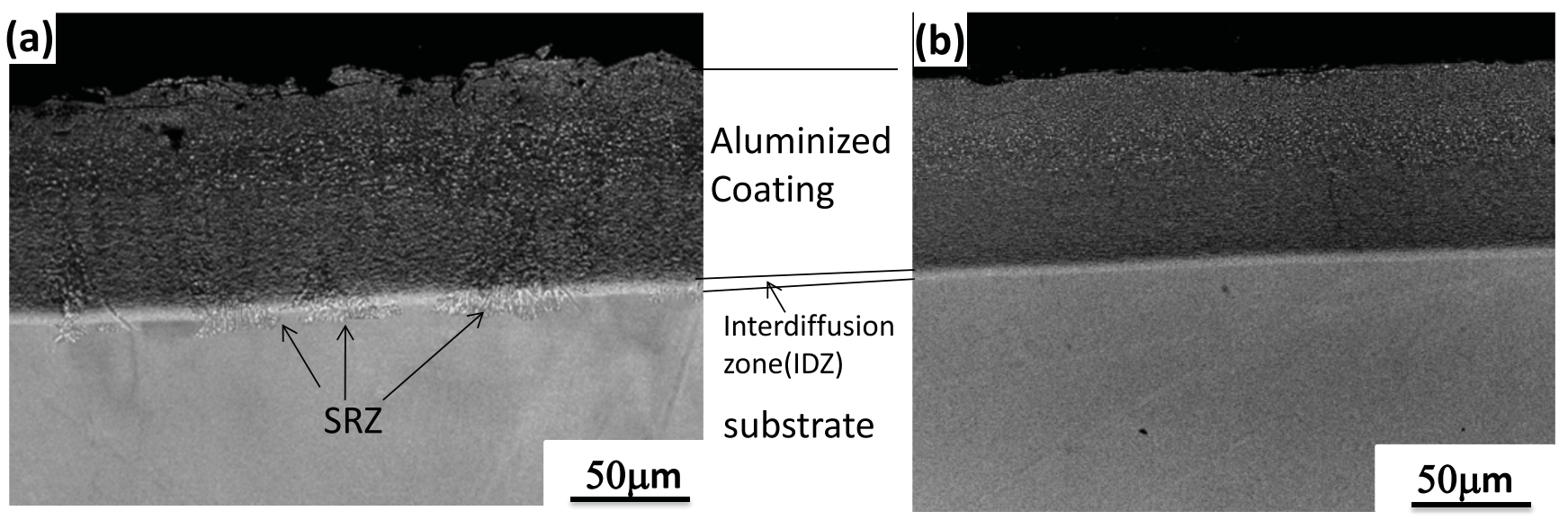

Figure 1. Cross-sectional BSE images of as-aluminized coatings on TMS-138, where $\{110\}$ oriented substrate surfaces are (a) grid blasted and (b) electropolished[17].

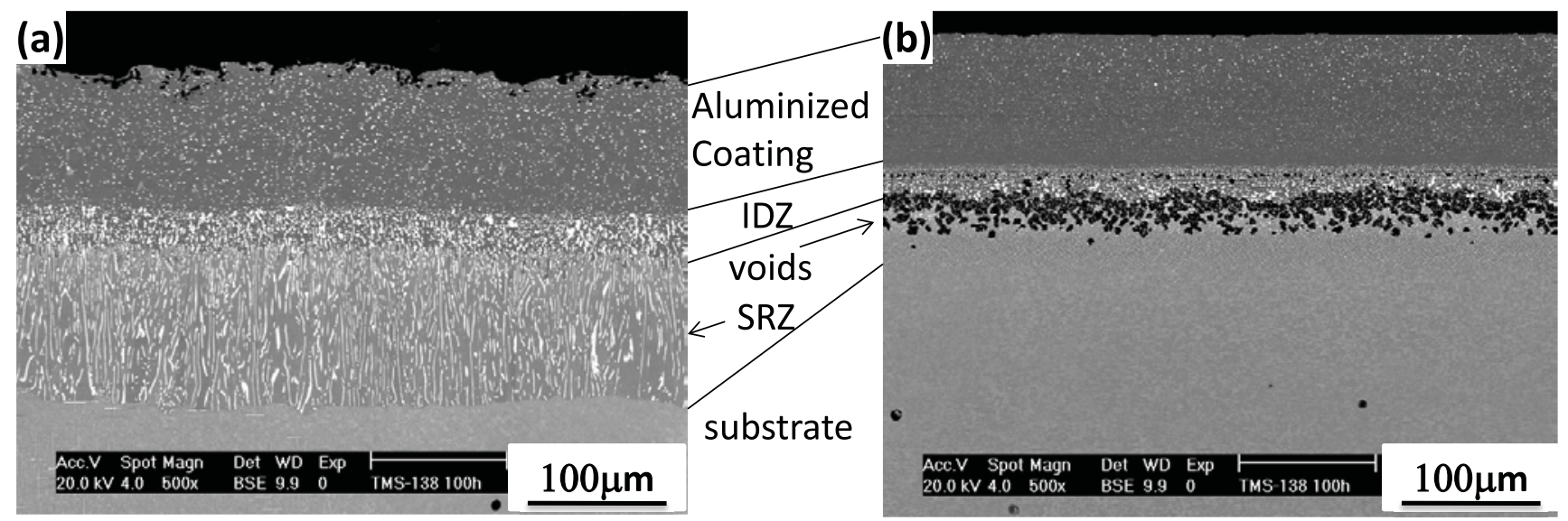

Figure 2. Cross-sectional BSE images after 100 thermal cyclic exposure, where $1 \mathrm{~h}$ heating at $1373 \mathrm{~K}$ followed by air cooling is defined as 1 cycle. Substrate surfaces are $\{110\}$ oriented and (a) blasted and (b) electropolished [17]. 
blasting). The substrate materials were then subjected to a conventional aluminizing process, where specimens were embedded in a heat-resistant container with a powder mixture of 24.5 mass $\% \mathrm{Al}, 24.5$ mass $\% \mathrm{Cr}, 49.0$ mass $\% \mathrm{Al}_{2} \mathrm{O}_{3}$ and 2.0 mass $\% \mathrm{NH}_{4} \mathrm{Cl}$. The container was set into an aluminizing furnace and heated at $1273 \mathrm{~K}$ in flowing Ar. By the aluminizing treatment, an Al-enriched surface with 50 to $55 \mathrm{Al}$ at \% was formed, confirming that the aluminizing process in this study was regarded as transit region between low-activity and high-activity process.

In order to investigate the effects of thermal exposure on microstructural evolution, the aluminized specimens were exposed to air, either thermally cycled, $(1373 \mathrm{~K}$ for $1 \mathrm{~h}$ and cooling for $20 \mathrm{~min}$ in air as one cycle) or isothermally exposed (1373 K up to $100 \mathrm{~h}$ ). These thermal exposures were also used for

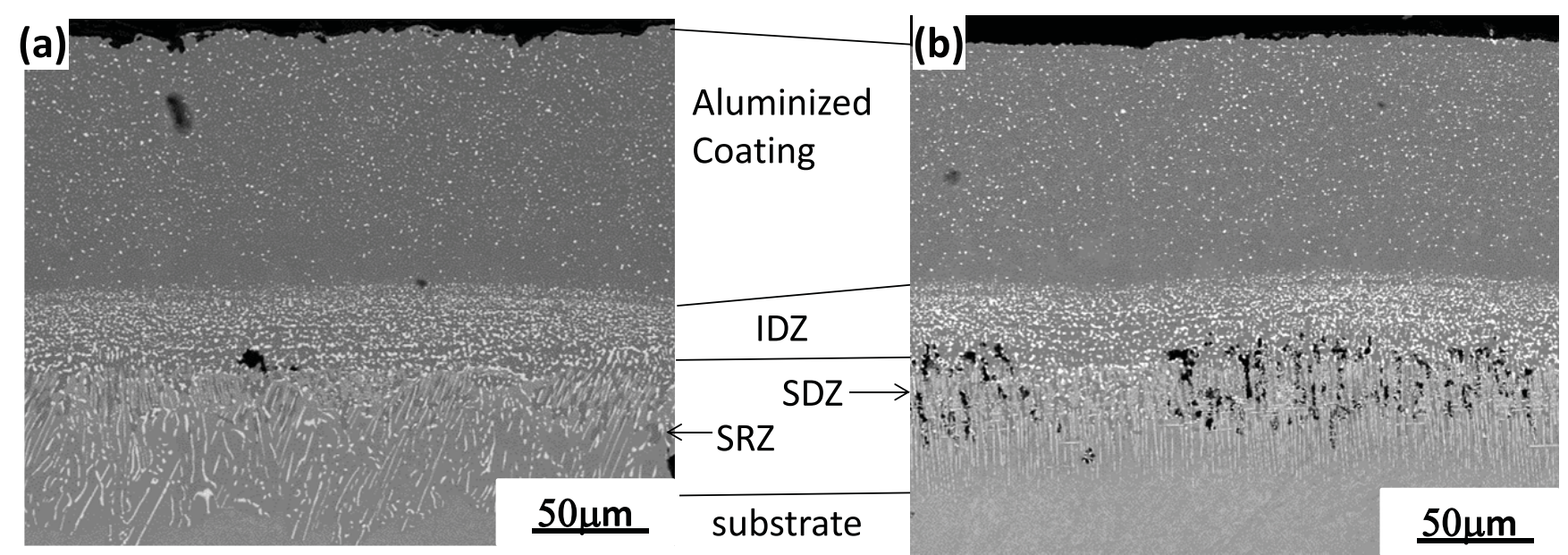

Figure 3. Cross-sectional BSE images of as-aluminized coatings on TMS-138, where (110) oriented substrate surfaces are (a) blasted and (b) electropolished

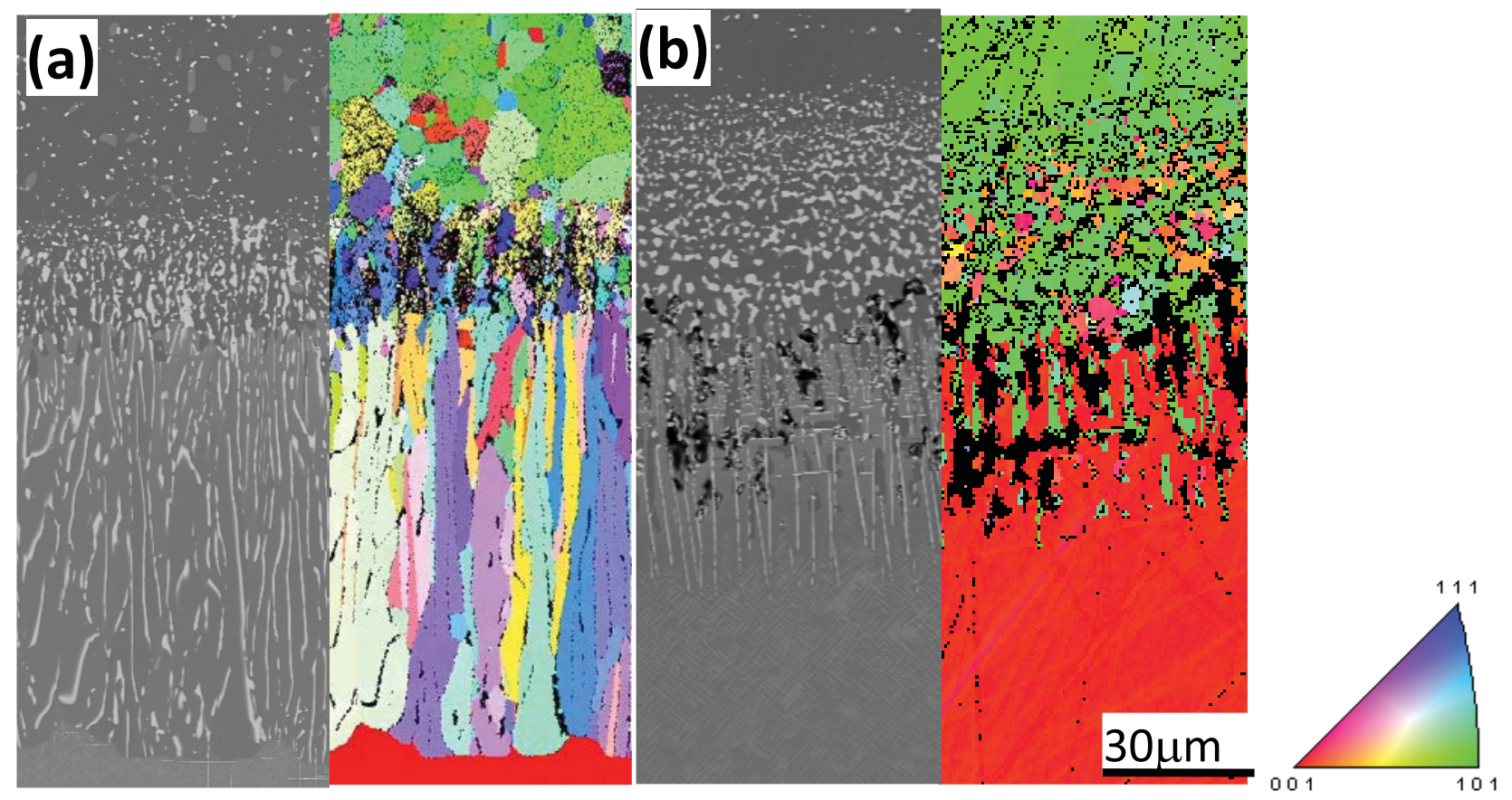

Figure 4. Magnified image of Figure 3 and corresponding EBSD orientation mapping; (a) substrate surface re-crystallization was observed whereas (b) precipitation of TCP phase without surface recrystallization, confirming that in the case of blasted surface, SRZ is formed while electropolished surface leads to the formation of SDZ. Orientation mapping is displayed normal to the observing plane. 
Table II Summary in microstructure changes of aluminized TMS-138

\begin{tabular}{llll|}
\hline Surface finish & Surface recrystallization & Cyclic-thermal exposure & Isothermal exposure \\
\hline Electro (or mechanical)-polished & No & Void formation & SDZ \\
Grit blasted & Yes & SRZ formation & SRZ (+SDZ) \\
\hline
\end{tabular}

oxidation tests. Specimens tested were analyzed using scanning electron microscopy (SEM), electro probe micro-analyzer (EPMA), and electron backscatter diffraction (EBSD) analysis

\section{Results and Discussions}

As indicated in the introduction section, microstructure of substrates drastically changed depending on various conditions. In this section, we will introduce typical differences in microstructural changes.

\section{Effect of Surface Finishing and Thermal History}

Figure 1 shows cross-sectional BSE images of as-aluminized coatings conducted on (a) grit-blasted and (b) electropolished surfaces. TMS-138 was used as the substrate material and substrate surface is along the $\{110\}$ plane. The rougher coating surface on the blasted specimen, as shown in Figure 1 (a) indicated that rougher substrate surface prior to the aluminizing gives rise to the rougher coating surface roughness. More importantly, SRZ formation was already observed in the blasted specimen, while such SRZ was not formed in the electropolished one. It is also confirmed that SRZ formation accelerates the inward microstructural changes, thus thickness of substrate affected zone is much larger in the grit-blasted specimens. When these specimens are exposed at elevated temperature, microstructure change takes place in the substrate, but in a different manner. Figure 2 shows the cross sections of aluminized specimens after 100 cycles of thermal exposure. The surface crystal orientation is along $\{110\}$ for both specimens. In the blasted specimen, SRZ grew and developed up to $100 \mu \mathrm{m}$ while void formation was observed in the electropolished specimens and after 100 thermal cycles, void formation region extended to approximately $10 \mu \mathrm{m}$, as shown in Figure 2(b). As reported, creep properties of aluminized superalloy can be determined by the effective cross section of un-damaged superalloy substrates [3], thus it can be induced that the electropolished specimen, with smaller substrate microstructure change can have an advantage in terms of creep.

On the other hand, when the isothermal exposure was applied to the specimens, different types of microstructure changes were observed, especially for the case of electropolished specimens. In figure 3(b), TCP phases are observed and microstructure of TCP phase precipitation zone is very similar to grit blasted specimens, as shown in Figure 2 (a) and Figure 3 (a). However, EBSD analysis revealed that while grid blasted specimens demonstrated substrate surface recrystallization together with the TCP precipitation (Figure 4(a)), there is no surface recrystallization observed, as shown in Figure 4(b). In the latter case, the TCP precipitation region is termed as a secondary diffusion zone

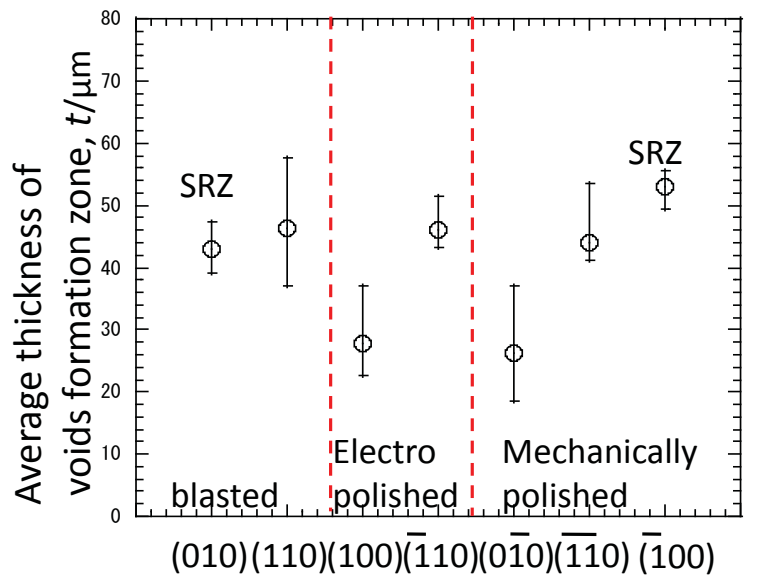

Figure 5. Thicknesses of the void formation layer and SRZ after exposed for 100 heat cycles at $1373 \mathrm{~K}$ [17].

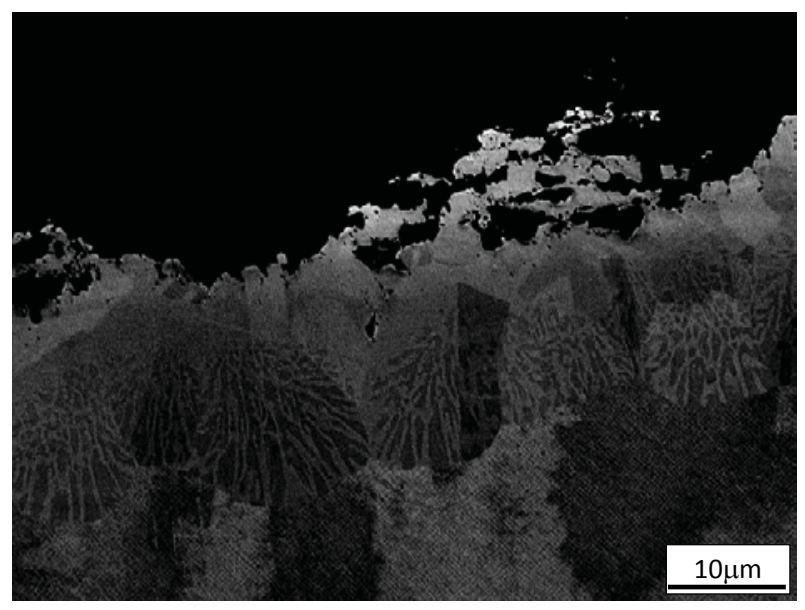

Figure 6. Cross-sectional microstructure of TMS-138 whose surface was heavily grid-blasted followed by Ar annealing at $1373 \mathrm{~K}$ for $1 \mathrm{~h}$, showing surface recrystallization. 


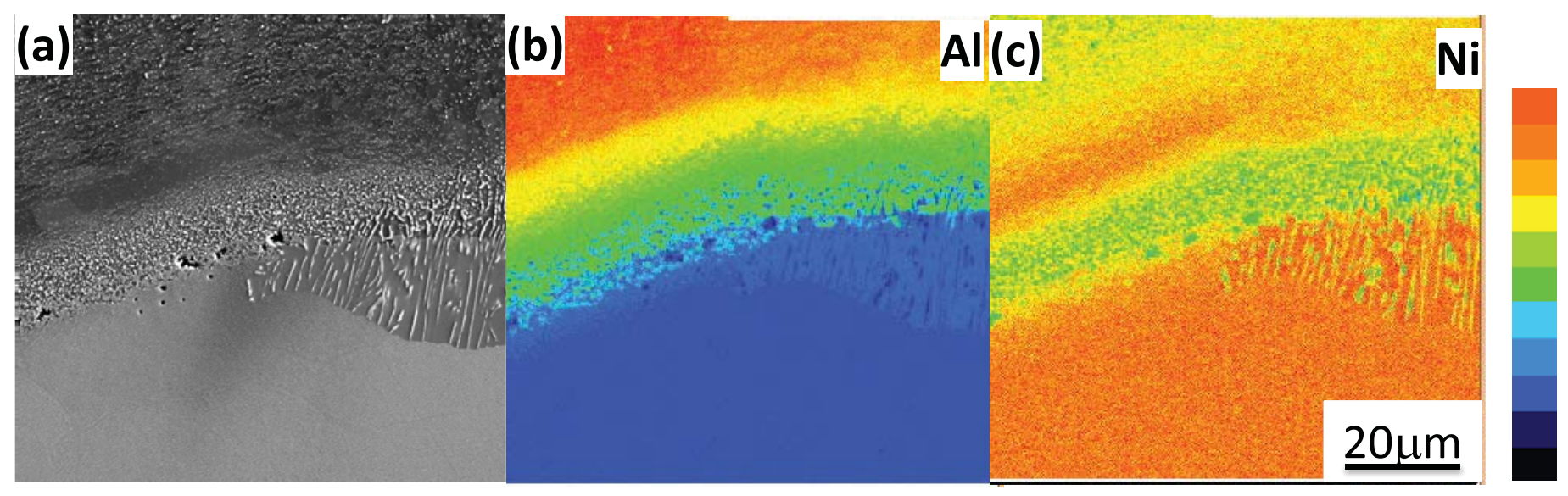

Figure 7. (a) Cross-sectional SE images of aluminized TMS-138 after 3-cycle-exposure, showing the SRZ-free sone on the left and SRZ-formation zone, and corresponding concentration mapping of (b)Al and (c)Ni, respectively. This figure confirms that inward diffusion of $\mathrm{Al}$ and outward diffusion of $\mathrm{Ni}$ are accelerated in the SRZ formation zone, due to the grain boundary diffusion.

(SDZ) [20]. The main difference between SRZ and SDZ can be explained by the occurrence of surface recrystallization of substrates.

\section{Effect of Surface Crystal Orientation}

Table II summarizes the microstructure changes of aluminized specimens after hear exposure. It is reported that in some cases, SRZ was preferentially observed along the $\{001\}<110>$ directions, but not observed along the $\{001\}<100>$ directions. In this study, such drastic difference in microstructure was not observed. Nevertheless, it was confirmed that microstructure changes such as void formation region and SRZ region were slightly more promoted along $<110>$ directions rather than $<100>$ directions, as shown in Figure 5, in which plots assigned as "SRZ" indicate thicknesses of SRZ, instead of void formation region.

\section{$\underline{\text { Microstructure Evolution Kinetics }}$}

Formation of SRZ can be explained by the residual strain applied by the grid blasting process, which leads to the surface recrystallization at the heating stage. It should be noted that such surface recrystallization occurs not only during aluminizing process, but also by the simple annealing treatment. Figure 6 is the cross-sectional microstructure of TMS-138 on which heavy grid blasting was applied followed by the annealing treatment at $1273 \mathrm{~K}$ for $10 \mathrm{~h}$, clearly showing the surface recrystallization, with several $10 \mu \mathrm{m}$ depth from the surface. Similar microstructure was observed when the CMSX-4 surface was heavily machined and heat treated [21].Once recrystallization takes place, following aluminizing process could preferentially promote the inward diffusion of $\mathrm{Al}$ and outward diffusion of $\mathrm{Ni}$, via grain boundaries. EPMA elemental mapping of $\mathrm{Al}$ and $\mathrm{Ni}$ in Figure 7 supports this hypothesis, where distribution of $\mathrm{Al}$ and $\mathrm{Ni}$ drastically differs between SRZ forming region and informing region.

It should also be noted that in the initial stage of SRZ, there are a number of twin boundaries observed as shown in Figure 8. In the fcc Ni-based superalloy, main slip systems are $\{111\}<110>$ and $\{111\}<112>$ and the latter slip forms twin boundaries. This

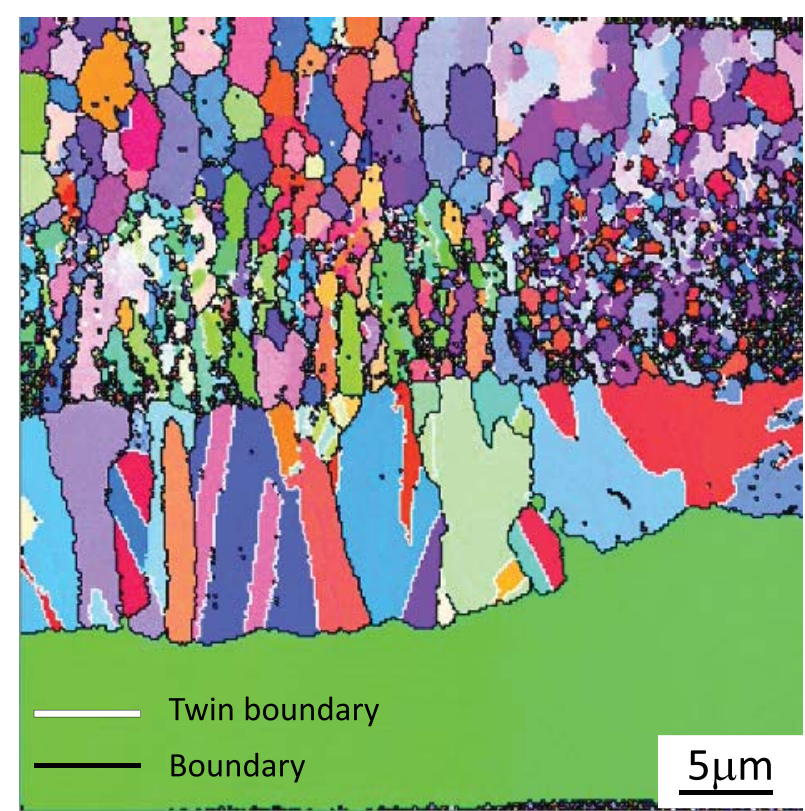

Figure 8. EBSD orientation mapping of the initial stage of SRZ formation, where a number of twin boundaries are formed, suggesting that grain boundaries are mainly formed along $\{111\}$ slip planes. Orientation mapping was taken normal to the substrate surface.

results suggests that surface recrystallization proceeds with $\{111\}$ grain boundaries.

In order to understand the formation and growth kinetics of SRZ, grid blasted substrates with varied blasting stress was prepared. Applied blasting pressures were $3,4,5 \mathrm{MPa}$ and $\mathrm{Ra}$ were estimated to $2.6,2.9$, and $3.8 \mu \mathrm{m}$, respectively. They were then subjected to the aluminizing treatment. Hereafter, These samples 


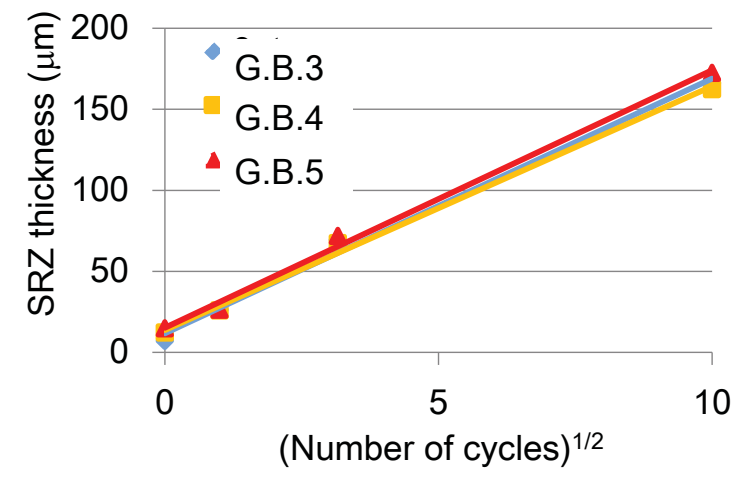

Figure 9. Relationship between number of heat exposure cycles and SRZ thickness, showing that growth of SRZ is diffusion controlled, and surface deformation is only affected by the initial SRZ thickness in the as-aluminized stage.

were denoted as G.B. 3, G.B.4, G.B.5, named after applied blasting pressures, For instance, G.B. 3 was treated with 3 bar of blasting pressure. As expected. SRZ was observed for all the as aluminized specimens, and the initial SRZ thickness increased with increasing grid blasting pressure, i.e. $7 \mu \mathrm{m}$ for G.B.3, $12 \mu \mathrm{m}$ for G.B.4 and $15 \mu \mathrm{m}$ for G.B.5, respectively. This result also supports that surface recrystallization precedes the SRZ formation.

On the other hand, it is found that further growth of SRZ is diffusion controlled. Figure 9 plots the relationship between thermal cycle number and SRZ thickness. SRZ thickness linearly increased with the root of thermal cycles, and the slope of the lines are almost identical to each other, which indicates that growth of SRZ is controlled by the interdiffusion of solute elements and is not affected by the initial surface deformation. Similar SRZ growing kinetics is reported in [12].

From these results, microstructural evolution of aluminized Nibased superalloys can be summarized in the following manner.

First of all, residual strain induced by the surface pre-treatment determines whether surface recrystallization takes place or not. It is well known that the dominant slip systems for Ni-based superalloys are $\{111\}<110>$ and $\{111\}<112>$. Stress induced local deformation of substrate surfaces and subsequent surface recrystallization could occur along these slip systems. While the cross-slip should operate to retard the local deformation along the $<100\rangle$ directions, such as $\langle 110\rangle$ along which the cross slip system did not work would suffer from further deformation. From these results it is speculated that there are critical amounts of surface residual stresses /strains which lead to surface recrystallization during the aluminizing process. Then the increase in surface residual strains by the surface treatment would lead to the following phenomena: i) no surface recrystallization on all the surfaces $\rightarrow$ ii) surface recrystallization along the $<110>$ directions but not along the $<100>$ directions $\rightarrow$ surface recrystallization for all the surfaces. The accelerated formation of SRZ along $<110>$ direction can be explained in the same way. The quantitative investigation for confirming this hypothesis is now being undertaken.

Once surface recrystallization occurs, SRZ formation takes place. And the SRZ growths kinetics is diffusion controlled.

On the other hand, surface recrystallization did not occur by the aluminizing process, SRZ was not observed by either cyclicthermal or isothermal exposure. Formation mechanism of voids by the thermal cyclic exposure is still under investigation, even though difference in thermal expansion coefficients between the fcc substrate and bcc coated layer may have caused the diffusion divergence.

\section{$\underline{\text { Oxidation Resistance }}$}

To understand the relationship among surface crystal orientation, pre-surface treatment and oxidation resistance, the thermal cycling test was conducted for four kinds of specimens, whose surfaces are either $\{100\}$ or $\{110\}$ oriented and finished with mechanical polishing or grid blasting, since the previous study confirmed that

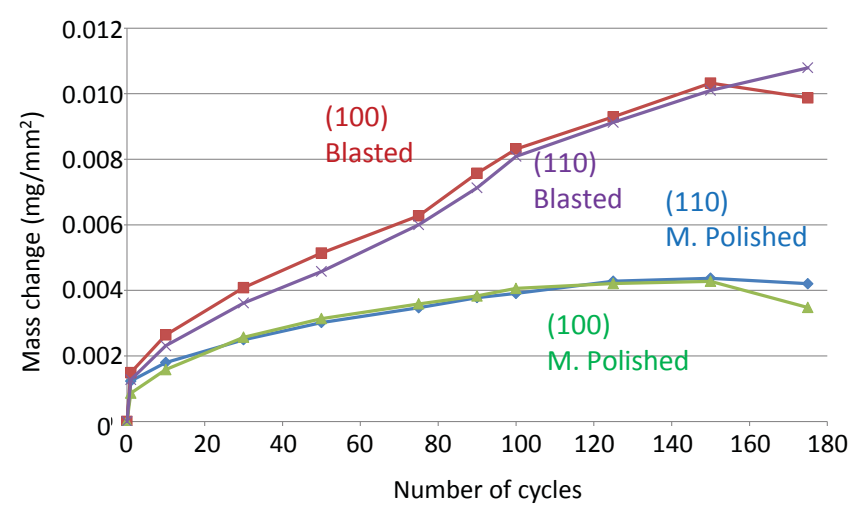

Figure 10. Kinetic oxidation curves as a function of thermal cycles.

specimens whose surface finished with mechanical polishing and electro-polishing behaved almost similarly to each other. Then the samples were aluminized in the same manner as the previous section. Note that UCSX-8 was used as the substrate single crystal superalloy and microstructural evolution of aluminized UCSX-8 is similar to that of aluminized TMS-138. Figures 10 and 11 show the kinetic oxidation curves and corresponding change in surface appearances of (a)mechanically polished (100), (b)blasted (100), (c)mechanically polished (110) and (c) blasted (110), as a function of thermal cycles, respectively. While there is a difficulty in differentiating the surface morphology among the four samples, sample mass measurement revealed that blasted specimens demonstrated accelerated mass gain compared to mechanically polished ones. However, the effect of surface crystal orientation has not been clarified so far. In order to understand oxidation protection mechanism, diffusion between the $\beta$-NiAl coated layer and the $\gamma / \gamma^{\prime}$ substrate [23], as well as the orientation relationship between the specimen surface and the $\mathrm{Al}_{2} \mathrm{O}_{3}$ scale [24] should be considered. Further investigation is thus required to understand the relationship between the microstructure changes and oxidation resistances. 


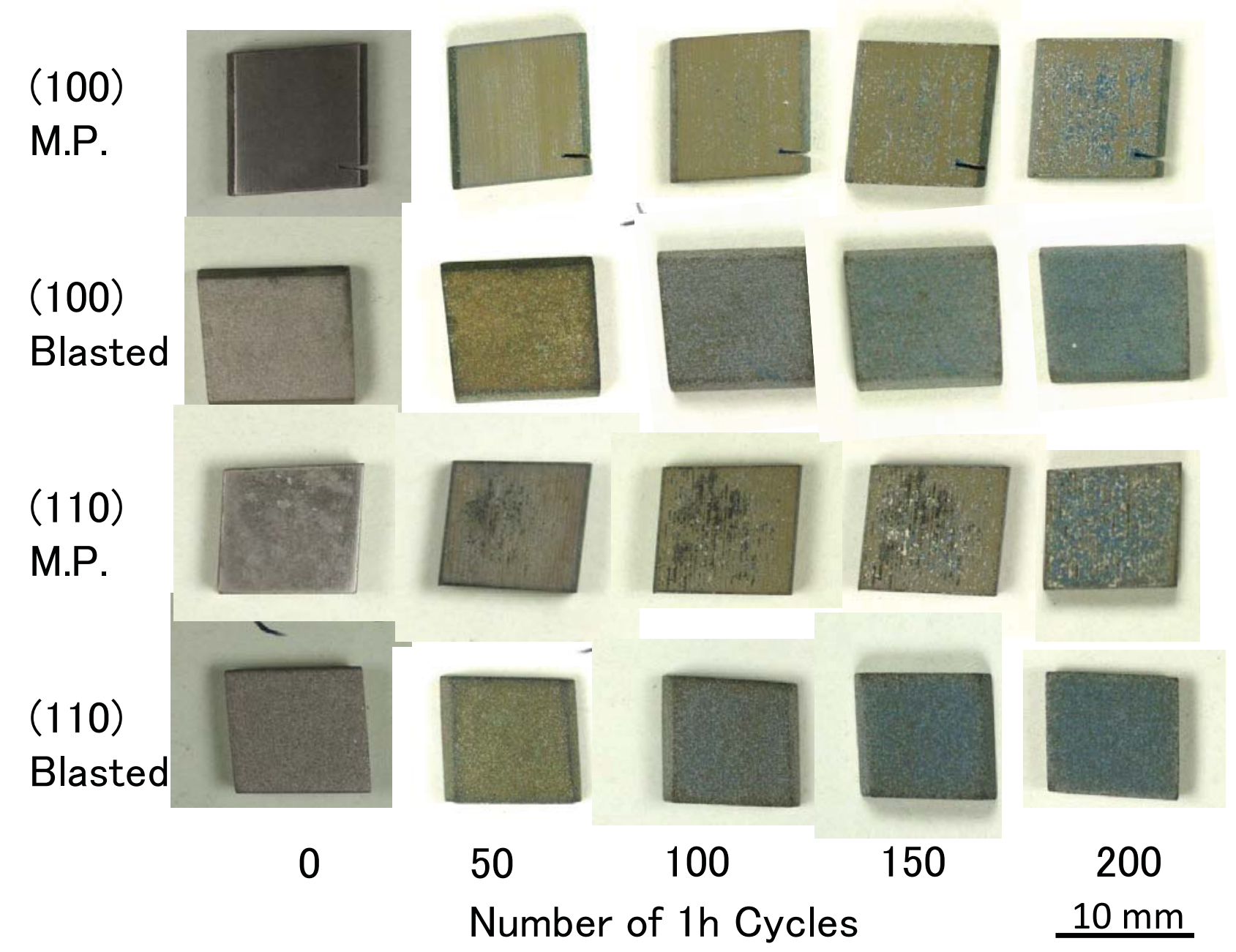

Figure 11. Change in surface appearances of aluminized UCSX-8 as a function of thermal cyclic exposure at $1373 \mathrm{~K}$ for $1 \mathrm{~h}$ as one heat cycles.

\section{Conclusions}

The effects of pre-surface finishing and surface crystal orientation on microstructural changes and oxidation resistance of simplyaluminized Ni-base single crystal superalloys were systematically investigated, and the following results were obtained.

1. Secondary reaction zone (SRZ), secondary diffusion zone (SDZ) and void formation were observed, where, SRZ accompanies surface recrystallization while surface recrystallization was not observed in the SDZ or void forming specimens.

2. It is suggested that surface recrystallization occurs during the initial stage of aluminizing process, resulting in the accelerated diffusion between the coated layer and the substrate. Consequently, SRZ formation takes place.
3. Surface recrystallization mainly occurs along $\{111\}$ plane, ainly occurs along $\{111\}$ plane,thus initial SRZ forms surrounded by $\{111\}$ planes.

4. Surface recrystallization was caused by the pre-surface finishing (grit blasting) and the initial SRZ thickness increased with increasing grid blasting pressure and subsequent SRZ growth is diffusion controlled.

5. Microstructure change of substrate is accelerated along $<110>$ direction rather than $<100>$ direction. However, orientation effect seems less significant than surface pretreatment effect.

6. Grit-blasted SRZ forming specimens have worse oxidation resistance than mechanically polished specimens.

7. It is suggested that SRZ formation also accelerates the inward diffusion of $\mathrm{Al}$, thereby decrease in surface $\mathrm{Al}$ concentration is faster in SRZ forming specimens rather than void forming specimens. 


\section{Acknowledgement}

The authors are grateful to IHI for supplying TMS-138 and to Prof. Sammy Tin for supplying UCSX-8, respectively.

\section{References}

1 S. Wöllmer, S. Zaefferer, M. Göken, T. Mack, U. Glatzel, "Characterization of phases of aluminized nickel base superalloys", Surface and Coatings Technology, 167(2003), 8396.

2 D. K. Das, K. S. Murphy, S. Ma and T. M. Pollock, "Formation of Secondary Reaction Zones in Diffusion Aluminide-Coated Nibase Single-Crystal Superalloys Containing Ruthenium", Metallurgical and Materials Transactions A39(2008), 1647-1657.

3 A. Sato, Y. Aoki, M. Arai and H. Harada, "Effect of Aluminized diffusion coatings on creep lives of Ni-based single crystal superalloys", J. Japan Inst. Metals. 71(2007) 320-325 (in Japanese).

4. W. S. Walston, J. C. Schaeffer, W. H. Murphy, “A New Type od Microstructural Instability Superalloys - SRZ", Superalloys 1996 (1996) pp. 9-18.

5. A. Suzuki, C. M. F. Rae, M. Yoshida, Y. Matsubara and H. Murakami, "Secondary Reaction Zones in Coated 4th Generation Ni-Based Blade alloys", Superalloys 2008, (2008) pp. 777-786.

6. T. Sakai, M. Shibata, H. Murakami and S. Kuroda "Microstructural Investigation of CoNiCrAlY Coated Ni-Based Single Crystal Superalloy Prepared by LPPS", Materials Transactions, 47(2006), pp 1665-1670.

7. R. Wang, X. Gong, H. Peng, Y. Ma and H. Guo, "Interdiffusion Behavior between NiAlHf Coating and Ni-based Single Crystal Superalloy with Different Crystal Orientations", Applied Surface Science, 326(2015), 124-130.

8. J. Zhong, J. Liu, X. Zhou, S. Li, M. Yu and X. Xu, "Thermal Cyclic Oxidation and Interdiffusion of NiCoCrAlYHf Coatings on a Ni-based Single Crystal Superalloy", Journal of Alloys and Compounds, 657(2016), 616-625.

9. P. Ren, S, Zhu and F. Wang, "Microstructure and Oxidation Behavior of a Ni+CrAlYSiHfN/AlN Multilayer Coating Fabricated by Reactive Magnetron Sputtering”, Corrosion Science, 104(2016), 197-206.

10. C. M. F. Rae, M. S. Hook and R. C. Reed, "The Effect of TCP Morphology on the Development of Aluminide Coated Superalloys", Materials Science and Engineering A396(2005), 231-239.

11. D. K. Das, B. Gleeson, K. S. Murphy, S. Ma and T. M. Pollock, "Formation of Secondary Reaction Zone in Ruthenium Bearing Nickel Based Single Crystal Superalloys with Diffusion Aluminide Coatings", Materials Science and Technology, 25(2009), 300-308.
12. Y. Matsuoka, Y. Aoki, K. Matsumoto, A. Satou, T. Suzuki, K. Chikugo and K. Murakami, "The Formation of SRZ on a Fourth Generation Single Crystal Superalloy Applied with Aluminide Coating", Superalloys 2008, (2008) pp 637-642.

13. I. M. Edmonds, H. E. Evans, C. N. Jones, "Oxidation \& Coating Evolution in Aluminized Fourth Genaration Blade Alloys”, Superalloys 2008, (2008) pp 661-670.

14. H. Murakami and T. Sakai, "Anisotropy of Secondary Reaction Zone Formation in Aluminized Ni-based Single-Crystal Superalloys", Scripta Materialia, 59(2008), 428-431.

15. F. H. Latief, K. Kakehi and H. Murakami, "Anisotropic Creep Properties of Aluminized Ni-Based Single-Crystal Superalloy at Intermediate and High Temperatures", Scripta Materialia 68(2013), pp126-129.

16. K. Kakehi, F. H. Latief and T. Sato "Influence of Primary and Secondary Orientations on Creep Rupture Behavior of Aluminized Single Crystal Ni-based Superalloy", Materials Science and Engineering A604(2014), 148-155.

17 K. Kasai, H. Murakami, S. Kuroda and H. Imai, "Effect of Surface Treatment and Crystal Orientation on Microstructural Changes in Aluminized Ni-Based Single-Crystal Superalloy", Materials Transactions 52(2011), 1768-1772.

18 K.Kasai, H. Murakami, and K Noda, "Effect of Thermal History on Microstructural Changes in Aluminized Nickel-Based Single-Crystal Superalloy, Materials Transactions 54(2013), 2252-2257.

19. H. U. Hong, J. G. Yoon, B. G. Choi, I. S. Kim and C. Y. Jo, "On the Mechanism of Secondary Reaction Zone Formation in a Coated Nickel-Based Single-Crystal Superalloy Containing Ruthenium", Scripta Materialia 69(2013) 33-36.

20. X. Gong, H. Peng, Y. Ma, H. Guo and S. Gong, "Microstructure Evolution of an EB-PVD NiAl Coating and its Underlying Single Crystal Superalloy Substrate", Journal of Alloys and Compounds, 672(2016) 36-44.

21. M. Okazaki, I. Ohtera and Y. Harada, "Damage Repair in CMSX-4 Alloy without Fatigue Life Reduction Penalty" Metallurgical and Materials Transactions, 35A(2004), 535-514.

22 Z. Zhang, B. Gleeson, K. Jung, L. Li and J. C. Yang, "A Diffusion Analysis of Transient Subsurface $\gamma$ '- $\mathrm{Ni}_{3} \mathrm{Al}$ Formation during $\beta$-NiAl Oxidation", Acta Materialia, 60(2012), 5273-5283.

23. Z. Zhang, L. Li and J. C. Yang, " $\gamma-\mathrm{Al}_{2} \mathrm{O}_{3}$ Thin Film Formation via Oxidation of $\beta-\mathrm{NiAl}(110)$ ", Acta Materialia, 59(2011), 5905-5916. 